\title{
Hypervalent lodine-based Trifluoromethylating Agents Made in Switzerland
}

\author{
Nico Santschi, ${ }^{{ }^{*}}$ and Antonio Togni ${ }^{\star b}$
}

\begin{abstract}
This account aims at providing a general overview over studies carried out in our group on 3,3-dimethyl1-(trifluoromethyl)-3H-1 $\lambda^{3}, 2$-benziodaoxole (1) and 1-(trifluoromethyl)-3H-1 $\lambda^{3}, 2$-benziodaoxol-3-one (2). While the first part deals with the syntheses of these increasingly popular reagents, the second part provides in-depth analyses of solid state structures of different derivatives. By means of bond-length derived parameters $p$ changes in the hypervalent bond resulting from backbone modifications could be classified. Furthermore, it is showcased that the parameter $p$ also correlates to solution phase reactivities. Lastly, diverse strategies directed towards the activation of the reagents are exemplified based on selected applications of $\mathbf{1}$ and $\mathbf{2}$.
\end{abstract}

Keywords: Electrophilic trifluoromethylation $\cdot$ Hypervalent iodine $\cdot$ Structure-reactivity relationship

\section{Introduction}

Over the past years, the introduction of the trifluoromethyl group into organic molecules has attracted considerable interest by the synthetic community due to $e . g$. its favorable effects on pharmacological profiles. For example, it was found that a single $\mathrm{CF}_{3}$ moiety $(\pi=0.88)^{[1]}$ can increase a structure's lipophilicity drastically. ${ }^{[2]}$ Furthermore, due to the high thermodynamic stability of the C-F bond (410-530 $\mathrm{kJ} / \mathrm{mol})^{[3]}$ the group may also be suited as a substitute for metabolically labile methyl functionalities. ${ }^{[4]}$ To date, several different methods for the incorporation of the $\mathrm{CF}_{3}$ group were developed from which only a few shall be highlighted. Thus, a $\mathrm{CCl}_{3}$ moiety can be converted to the desired motif by treatment with HF (functional group interconversion). ${ }^{[5]}$ Also, deoxofluorinations of carboxylic acids or carbamodithioates with either $\mathrm{SF}_{4}$ or Deoxofluor were found to be effective. ${ }^{[6]}$ More direct methods usually involve generation of the nucleophilic $\mathrm{CF}_{3}$ anion from either TMSCF $\mathrm{TM}_{3}$ (RuppertPrakash reagent) and catalytic amounts of fluoride, [7] or $\mathrm{CF}_{3} \mathrm{I}$ and stoichiometric amounts of tetrakis(dimethylamino)eth-

\footnotetext{
${ }^{\star}$ Correspondence: Dr. N. Santschia, Prof. A. Togni ${ }^{b}$ aWestfälische Wilhelms-Universität Münster Organisch-Chemisches Institut Corrensstrasse 40, D-48149 Münster

E-mail: santschi@uni-muenster.de

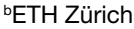

Laboratory of Inorganic Chemistry Vladimir-Prelog-Weg 2

$\mathrm{CH}-8093$ Zürich

E-mail: togni@inorg.chem.ethz.ch
}

ylene (TDAE) followed by addition to a suitable electrophile. ${ }^{[8]}$ Furthermore, the anion can also be generated through deprotonation of $\mathrm{CF}_{3} \mathrm{H}^{\text {[9] }}$ In addition, the electrophilic $\mathrm{CF}_{3}$ radical can, for example, be accessed from a mixture of $\mathrm{CF}_{3} \mathrm{I}$ and $\mathrm{BEt}_{3},{ }^{[10]}$ or $\mathrm{CF}_{3} \mathrm{I}$ and a photoredox catalyst and may be readily reacted with enamines, even in an enantioselective fashion. ${ }^{[11]}$ More recently, this radical was also generated through photoreduction of triflyl chloride or of the reagents 1 and 2. ${ }^{[12]}$

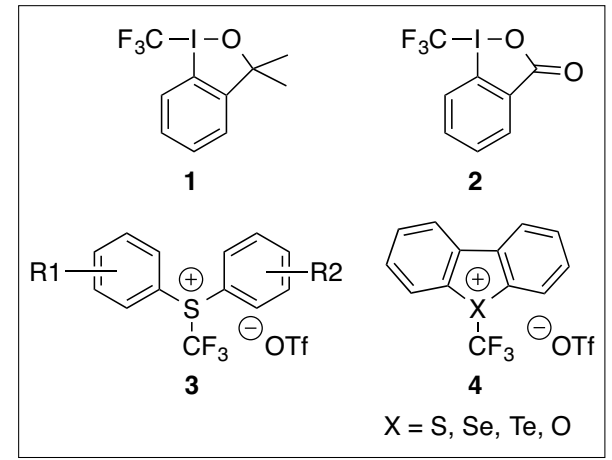

Fig. 1. Hypervalent iodine reagents $\mathbf{1}$ and $\mathbf{2}$, and Yagupol'skii (3) and Umemoto (4) type reagents.

The first successful synthesis of a $\mathrm{CF}_{3}$ cation equivalent was described by Yagupol'skii in the form of the (trifluoromethyl)diaryl sulfonium salts 3. ${ }^{[13]}$ Later, building on this chalcogenium concept, reagents 4 were devised by Umemoto and found to react with a very broad variety of nucleophiles (Fig. 1). ${ }^{[14]}$ Up to 2007, they were probably the most versatile and most applied electrophilic trifluoromethylation reagents available. Despite their reactivity, drawbacks such as difficult preparations have still been mostly unaddressed to this date. Sometimes also in situ generation of the active compound is required, e.g. for the unstable $O$-(trifluoromethyl)dibenzofuranium salts $4(\mathrm{X}=\mathrm{O})$. $^{[15]}$ Therefore, starting in 2006 we sought to address this problem by designing new stable sources for an electrophilic trifluoromethyl moiety based on a hypervalent iodine scaffold.

\section{Synthesis of the Reagents}

Initial attempts to obtain acyclic trifluoromethyl-carrying hypervalent iodine reagents through ligand exchange reactions starting from iodosyltoluene, (dichloroiodo)toluene and alike and $\mathrm{TMSCF}_{3}$ in presence of catalytic amounts of fluoride failed to deliver the desired species as judged from ${ }^{19} \mathrm{~F}$ NMR experiments. ${ }^{[16]}$ However, when difluoroiodobenzene in $\mathrm{MeCN}$ was treated with $\mathrm{TMSCF}_{3}$ in the absence of any other fluoride source, detectable amounts of $\mathrm{CF}_{3} \mathrm{I}$ were found. Furthermore, resonances corresponding to aromatic trifluoromethylation products were detected around $-60 \mathrm{ppm}$ by ${ }^{19} \mathrm{~F}$ NMR spectroscopy. Given that a weak $\mathrm{C}_{i p s o}-\mathrm{I}$ bond in the putative $\mathrm{PhI}\left(\mathrm{CF}_{3}\right)_{2}$ compound was present, a reductive elimination-type mechanism could have provided $\mathrm{PhCF}_{3}$ as well as $\mathrm{CF}_{3} \mathrm{I}$. Consequently, in order to increase the stability of the hypervalent reagent, a rigid backbone connecting one of the ligands to the aromatic core was to be introduced. In the end, based on precedence in the form of stable, isolable hypervalent chloroiodinanes featuring the benziodaoxole skeleton this approach led to the development of two key core structures that will be referred to as reagents of type I (e.g. 1) and type II (e.g. 2). ${ }^{[16,17]}$ 
The parent reagent 1 (type I) was initially accessed starting from the corresponding tertiary alcohol $\mathbf{5}$, followed by oxidation in DCM with $t \mathrm{BuOCl}$ to provide the hypervalent chloroiodinane 6 in $86 \% .{ }^{[18]}$ Most recently however, an alternative approach was established. Hence, oxidation of 5 to 6 was carried out with trichloroisocyanuric acid (TCICA) in MeCN achieving comparable yields $(89 \%)$ (Scheme 1). ${ }^{[19]}$ Subsequently, a quantitative chloride exchange mediated by AgOAc in $\mathrm{MeCN}$ or, with slightly diminished yields, ${ }^{[16]}$ under Finkelstein-type reaction conditions of KOAc in $\mathrm{MeCN}$ provided the acetoxy species 7 that was converted to the active reagent 1 . To this end, 7 is treated at $-17{ }^{\circ} \mathrm{C}$ with $\mathrm{TMSCF}_{3}$ (1.76 equiv) and catalytic amounts of tetrabutylammonium difluorotriphenylsilicate (TBAT, $0.3 \mathrm{~mol} \%$ ) resulting in the desired substitution in $85 \%$ yield. ${ }^{[18,20]}$ Commonly, we refer to this step as an Umpolung reaction. Conveniently, it was shown that isolation of the acetoxy intermediate (7) is not necessary, hence reducing the total number of steps required. Alternatively, $\mathbf{6}$ can also be transformed to the hypervalent fluoroiodinane $\mathbf{8}$ by stirring with $\mathrm{KF}$ ( 3 equiv) in $\mathrm{MeCN}$, followed by in situ treatment with $\mathrm{TMSCF}_{3}(1.1$ equiv) at $0{ }^{\circ} \mathrm{C}$ affording 1 in up to $91 \%$ yield. ${ }^{[19]}$ This protocol was found more practical and time-economical (Scheme 1). Generally, purification of type I reagents can be achieved by sublimation under high vacuum followed by low temperature recrystallization from pentane. When stored at $-17{ }^{\circ} \mathrm{C}$ these reagents show good longtime stability. Although sensitivity towards moisture was originally thought possible, this was not found to be the case and reactions with type I reagents may even be carried out in aqueous systems.

Two strategies for accessing type II reagents are currently known. 2-Iodobenzoic acid $(\mathbf{9})$ is oxidized with sodium periodate in water to 2-iodosylbenzoic acid (96\%, Scheme 2). Subsequent treatment with acetic acid anhydride followed by crystallization of the product provides the acetoxy precursor 10. ${ }^{[16]}$ The latter is readily converted with $\mathrm{TMSCF}_{3}$ and catalytic amounts of CsF to afford 2 (up to $76 \%$ ). Alternatively, the oxidation is achieved with $t \mathrm{BuOCl}$ or TCICA furnishing chloroiodinane $\mathbf{1 1}$ in excellent yields ( $>99 \%$ with TCICA). ${ }^{[19]}$ Finally, stirring with KOAc also provides the acetoxy intermediate 10. Moreover, building on the TCICA promoted oxidation a convenient one-pot procedure accessing $\mathbf{2}$ in up to $72 \%$ yield on a $15 \mathrm{~g}$ scale was realized. ${ }^{[19]}$ Therefore, after completion of the chlorination of 9 (5 mins), dry KOAc ( 2 equiv) was added to the slurry and the mixture was subsequently incubated for two hours at $75^{\circ} \mathrm{C}$. Finally, vigorous stirring with $\mathrm{TMSCF}_{3}$

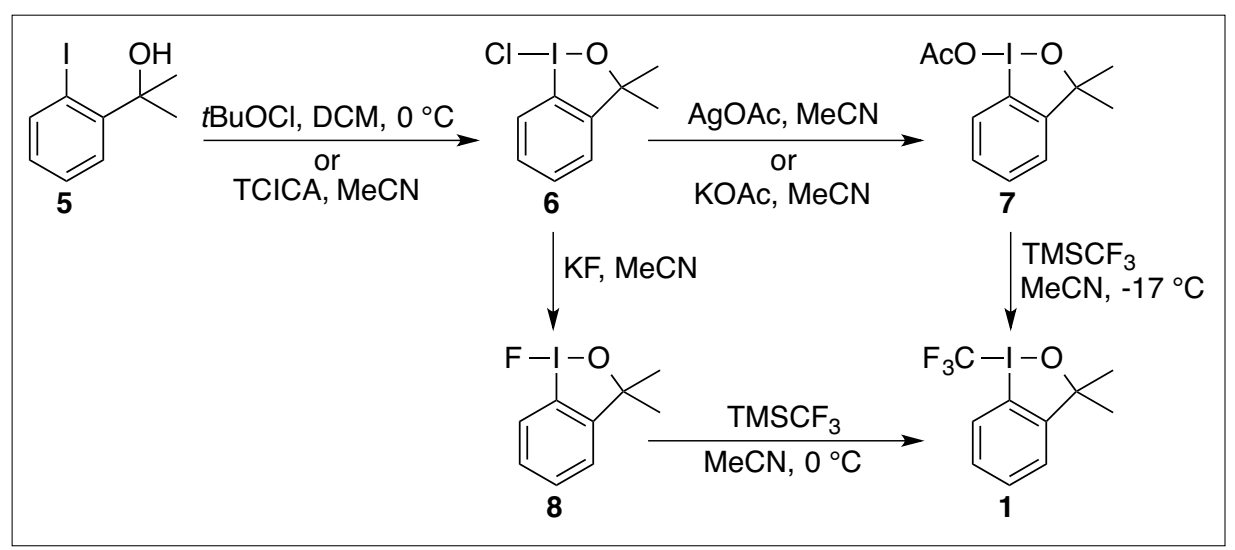

Scheme 1. Generalized synthesis of type I reagents.

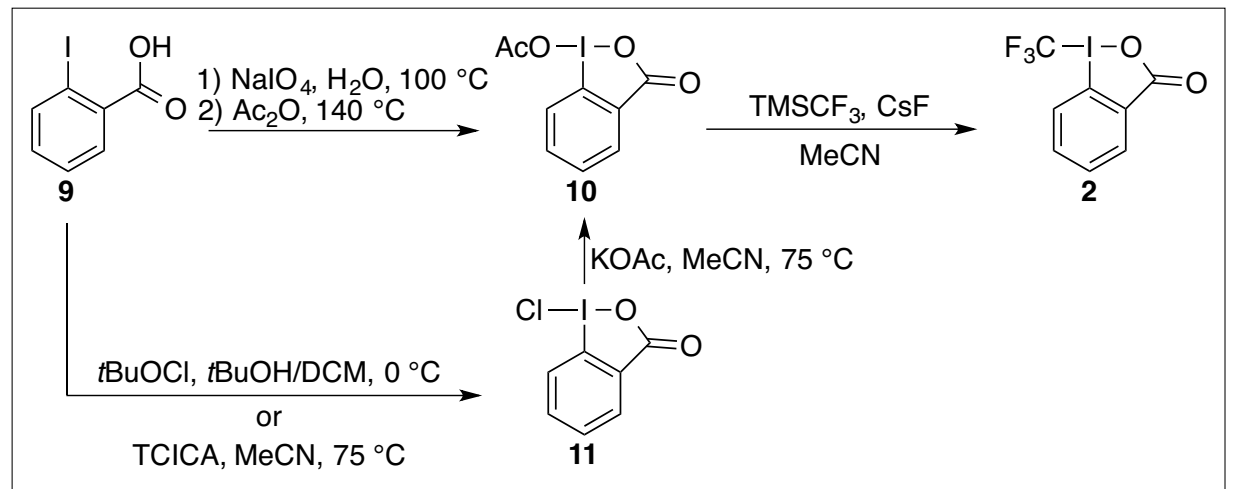

Scheme 2. Generalized synthesis of type II reagents.

(1.4 equiv) at room temperature for $12 \mathrm{~h}$ was followed by a hot filtration over Celite and isolation of the pure product by means of low temperature crystallization.

In contrast to reagents of type I, type II reagents were found to be stable at ambient temperature and may even be purified by column chromatography.

\subsection{Structure of Type I Reagents}

Since the initial synthesis of reagent 1, several new derivatives with the goal of finding more reactive structures have been accessed and reported. ${ }^{[21]}$ Both the precursor chloroiodinanes and the final reagents were characterized by X-ray crystallography and the most important bond lengths are given in Table 1.

With this data in hand, bond length correlations in the 1-chloro$1 \lambda^{3}, 2$-benziodaoxole $(\mathbf{6}, \mathbf{1 2} \mathbf{a}-\mathbf{1 5 a})$ and 1-trifluoromethyl-1 $\lambda^{3}, 2$-benziodaoxole $(\mathbf{1}$, 12b-15b) scaffolds (Fig. 2A) were sought. Consequently, plotting of $\mathrm{I}-\mathrm{O}^{1}$ versus $\mathrm{I}-\mathrm{Cl}$ and $\mathrm{I}-\mathrm{O}^{2}$ versus $\mathrm{I}-\mathrm{CF}_{3}$ suggested linear correlations between the two bonds, thereby implying that $\mathrm{I}-\mathrm{X}$ becomes increasingly weaker (i.e. longer) as the $\mathrm{I}-\mathrm{O}$ bond becomes shorter. Although at first sight analogous behavior is observed, closer examination of the data and residuals for the final reagents $(\mathbf{1}, \mathbf{1 2 b}-\mathbf{1 5 b})$ indicates that the correlation is more likely of a nonlinear nature. Therefore, bond length variations in $\mathrm{I}-\mathrm{O}^{2}$ between $2.20 \AA$ and $2.25 \AA$ will have a less pronounced effect on $\mathrm{I}-\mathrm{CF}_{03}$ and, conversely, variations around $2.10 \AA^{\circ 3}$ will have a larger effect.

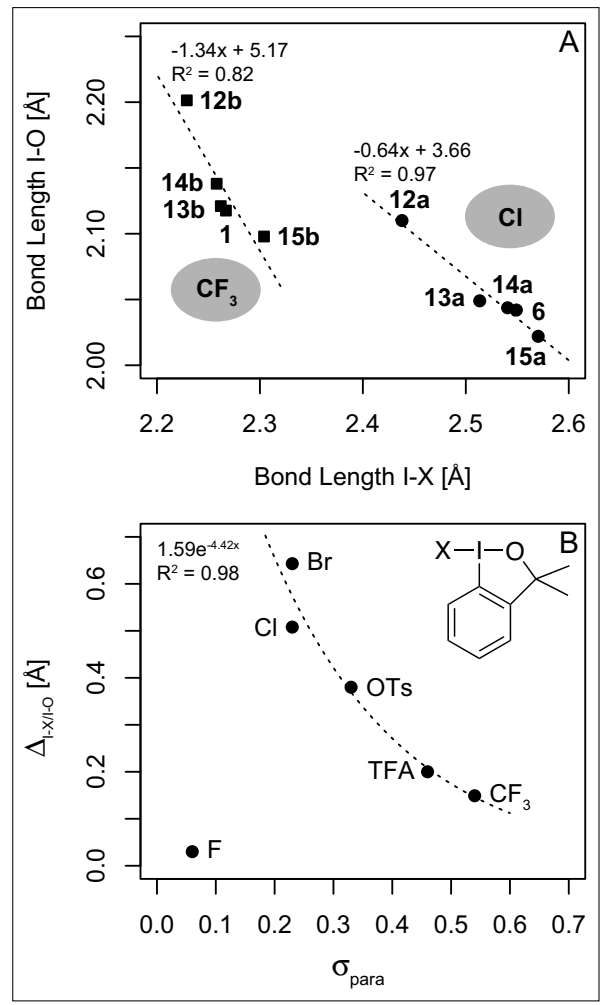

Fig. 2. Bond length correlations $\mathrm{I}-\mathrm{O}$ vs $\mathrm{I}-\mathrm{X}$ in compounds 6, 12a-15a and 1, 12b-15b (A). Exponential relationship $\ln \left(\Delta_{|-X|-0}\right) \sim \sigma_{\text {para }}$ for 3,3-dimethyl-1 $\lambda^{3}, 2$-benziodaoxole scaffold based reagents $(\mathrm{B})$. 
Table 1. Bond lengths of 1-chloro-1 $\lambda^{3}, 2$-benziodaoxoles, of corresponding 1-trifluoromethyl-1 $\lambda^{3}, 2-$ benziodaoxoles and average F-C-F angles
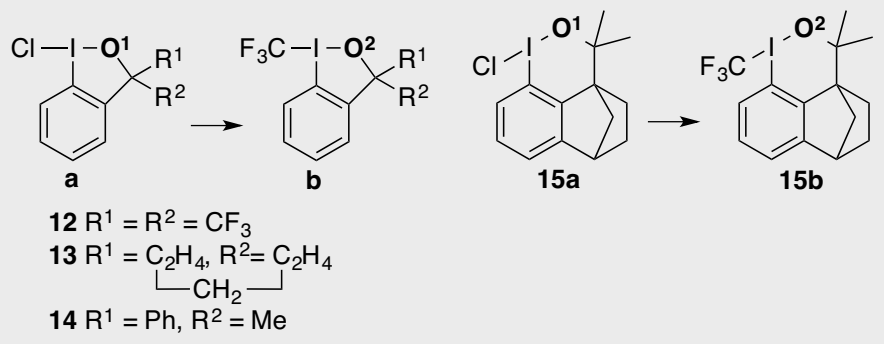

\begin{tabular}{|c|c|c|c|c|}
\hline Compound & $\mathbf{I}-\mathbf{X}[\mathbf{A}]$ & $\mathbf{I}-\mathbf{O}[\AA ̊ \cap]$ & $\Delta_{\text {I-XI-O- }}[\AA]^{\mathrm{a}}$ & F-C-F $\left[{ }^{\circ}\right]^{b}$ \\
\hline $6(\mathrm{X}=\mathrm{Cl})$ & $2.5491(8)$ & $2.042(2)$ & 0.507 & - \\
\hline 12a $(\mathrm{X}=\mathrm{Cl})$ & $2.438(2)$ & $2.110(5)$ & 0.328 & - \\
\hline 13a $(\mathrm{X}=\mathrm{Cl})$ & $2.5135(9)$ & $2.049(2)$ & 0.465 & - \\
\hline 14a $(\mathrm{X}=\mathrm{Cl})$ & $2.5406(7)$ & $2.0437(2)$ & 0.497 & - \\
\hline $15 \mathbf{a}(\mathrm{X}=\mathrm{Cl})$ & $2.5703(6)$ & $2.0220(15)$ & 0.548 & - \\
\hline $1\left(\mathrm{X}=\mathrm{CF}_{3}\right)$ & $2.267(2)$ & $2.1176(14)$ & 0.149 & $106.22 \pm 0.38$ \\
\hline $12 b\left(\mathrm{X}=\mathrm{CF}_{3}\right)$ & $2.229(2)$ & $2.2014(15)$ & 0.028 & $107.32 \pm 0.43$ \\
\hline $\mathbf{1 3 b}\left(\mathrm{X}=\mathrm{CF}_{3}\right)$ & 2.262(4) & $2.121(2)$ & 0.141 & $106.93 \pm 0.74$ \\
\hline $14 b\left(X=\mathrm{CF}_{3}\right)$ & $2.2580(14)$ & $2.1380(10)$ & 0.120 & $106.69 \pm 0.30$ \\
\hline $15 \mathbf{b}\left(\mathrm{X}=\mathrm{CF}_{3}\right)$ & $2.304(2)$ & $2.0979(14)$ & 0.206 & $106.34 \pm 0.10$ \\
\hline
\end{tabular}

${ }^{\mathrm{a}} \Delta_{\mathrm{I}-\mathrm{XI}-\mathrm{O}}$ is calculated by subtraction of I-O from I-X. ${ }^{\mathrm{b}}$ Average $\mathrm{F}-\mathrm{C}-\mathrm{F}$ angle and standard deviation in the O-I-CF ${ }_{3}$ moiety.

Moreover, calculation of $\Delta_{\mathrm{I}-\mathrm{X} / \mathrm{I} \mathrm{O}}$, as the difference between the bonds I-X and $\mathrm{I}-\mathrm{O}$, implies that conversion of the chloroiodinane precursors to the reagents also significantly changes the nature of the hypervalent bond. Whereas in compounds 6, 12a--15a the I-X bond is significantly longer than the $\mathrm{I}-\mathrm{O}$ bond, in compounds $\mathbf{1}, \mathbf{1 2 b}-\mathbf{1 5 b}$ this feature greatly diminishes and in structure $\mathbf{1 2 b}$ almost equally long bonds are observed. In order to gain further information describing the intricate interplay between the lengths of a general bond $\mathrm{I}-\mathrm{X}$ and the bond $\mathrm{I}-\mathrm{O}$ in hypervalent iodine reagents based on the 3,3-dimethyl$1 \lambda^{3}, 2$-benziodaoxole scaffold, a survey of previously published structures was compiled. Six suitable candidates with $\mathrm{X}=\mathrm{F}$, $\mathrm{Cl}, \mathrm{Br}, \mathrm{CF}_{3}, \mathrm{OC}(=\mathrm{O}) \mathrm{CF}_{3}$, OTs were identified in the Cambridge Structural Database and further investigated, extending on Ochiai's work on the trans influence on hypervalent bonding in $\lambda^{3}$-iodanes. ${ }^{[22]}$ The bond lengths of interest are presented in Table 2. Although no direct correlations between neither I-X vs I-O nor I-X or I-O vs $p$, where $p$ denotes a classical physicochemical parameter (Hammett, Taft, etc.), could be found, an exponential relationship of the sort $\ln \left(\Delta_{\text {I-X/I-O }}\right) \sim \sigma_{\text {para }}$ was uncovered (Fig. 2B). Generally, it was noted that the more electron-withdrawing the substituent $X$, the smaller the difference between the bonds I-X and I-O. Although this also holds true for $\mathrm{X}=\mathrm{F}$ with $\Delta_{\mathrm{I}-\mathrm{X} / \mathrm{IO}}$ $=0.03$, the compound was identified as an outlier when using $\sigma_{\text {para }}$ as a reference. Accordingly, this correlation should allow for describing the features of the hypervalent bond in this class of compounds by a single, easily determined parameter.

In consideration of the relationship $\ln \left(\Delta_{\mathrm{I}-\mathrm{X} / \mathrm{IO}}\right) \sim \sigma_{\text {para }}$, approximations for theoretical $\sigma_{\text {para }}(\mathrm{X})$ values of the $\mathrm{CF}_{3}$ moiety in the trifluoromethylating agents $1, \mathbf{1 2 b}-$ 15b can be calculated. ${ }^{[23]}$ Therefore, based on the values for $\Delta_{\mathrm{I}-\mathrm{X} / \mathrm{I}-\mathrm{O}}$ presented in Table 1 , the following estimates for $\sigma_{\text {para }}\left(\mathrm{CF}_{3}\right)$ are obtained: 0.51 (1), 0.64 (12b), 0.52 (13b), 0.54 (14b), 0.46 (15b). For example, these values imply that the electronic nature of the reagents $1, \mathbf{1 3 b}$ and $\mathbf{1 4 b}$ are comparable and therefore these structures would be expected to react with similar rates. An analogous conclusion is also drawn from estimates based on the chloroiodinane structures with $\sigma(\mathrm{Cl})=0.26(\mathbf{6}), 0.37$ (12a), 0.29 (13a), 0.27 (14a), 0.25 (15a).

Table 2. Bond lengths I-X and I-O of various hypervalent iodine reagents

\begin{tabular}{|c|c|c|c|c|}
\hline $\mathbf{X}$ & $\mathbf{I - X}[\AA ̊ \AA]$ & I-O [Å] & $\Delta_{\text {I-X/I-O }}[\AA]^{\mathrm{a}}$ & $\sigma_{\text {para }}{ }^{b}$ \\
\hline $\mathrm{F}$ & 2.046 & 2.016 & 0.03 & 0.06 \\
\hline $\mathrm{Cl}$ & 2.549 & 2.041 & 0.51 & 0.23 \\
\hline $\mathrm{Br}$ & 2.693 & 2.050 & 0.64 & 0.23 \\
\hline $\mathrm{CF}_{3}$ & 2.267 & 2.118 & 0.15 & 0.54 \\
\hline $\mathrm{OC}(=\mathrm{O}) \mathrm{CF}_{3}$ & 2.211 & 2.011 & 0.20 & 0.46 \\
\hline OTs & 2.361 & 1.981 & 0.38 & $0.33^{\mathrm{d}}$ \\
\hline
\end{tabular}

${ }^{\mathrm{a}} \Delta_{\mathrm{I}-\mathrm{XI} \text {-O }}$ is calculated by subtraction of I-O from I-X. ${ }^{\mathrm{b}}$ Preferred values from ref. [2]. ${ }^{\mathrm{c} A s y m m e t r i c}$ unit contains two independent molecules. ${ }^{d} \sigma_{\text {para }}$ not available. Estimated by $\sigma_{\text {para }}$ for $\mathrm{OS}(=\mathrm{O})_{2} \mathrm{Ph}$.

However, based on this series, only reagent 12a is projected to behave largely differently. Moreover, these theoretical $\sigma_{\text {para }}(\mathrm{X})$ values also carry information further describing the I-X bond lengths observed.

Commonly, hypervalent iodine compounds are described by the RundlePimentel model, constructing the 3-center4-electron bond from the $5 p_{z}$ orbital at iodine and ligand orbitals with $\mathrm{p}$-character (Fig. 3). [24]

\begin{tabular}{|c|c|c|c|}
\hline$\infty$ & $\infty$ & $\infty$ & - antibonding \\
\hline$\infty$ & & $\infty$ & f nonbonding \\
\hline$\infty$ & $\stackrel{\infty}{\infty}$ & $\infty$ & 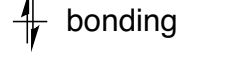 \\
\hline \multicolumn{4}{|c|}{$\mathrm{x}-\mathrm{I}-\mathrm{O}$} \\
\hline & $\mathrm{Ar}$ & $\mathrm{R}$ & \\
\hline
\end{tabular}

Fig. 3. Rundle-Pimentel model of hypervalent bonding.

Consequently, short I-X bonds are anticipated to result from a better overlap with iodine's $5 \mathrm{p}_{\mathrm{z}}$, implying a $\mathrm{p}$-characterrich ligand orbital - a situation empirically accompanied by a higher theoretical $\sigma_{\text {para }}(\mathrm{X})$ value for the same motif X (more 
affect the goodness of fit, the overall trend is evident and thus further substantiates the changes in hybridization occurring. Subsequently, after having identified the parameters $\sigma_{\text {para }}(\mathrm{X})$ to adequately represent these subtle changes in the electronic structure of the hypervalent $\mathrm{CF}_{3}-\mathrm{I}-\mathrm{O}$ bond, results from solution phase reactivity studies were reconsidered next.

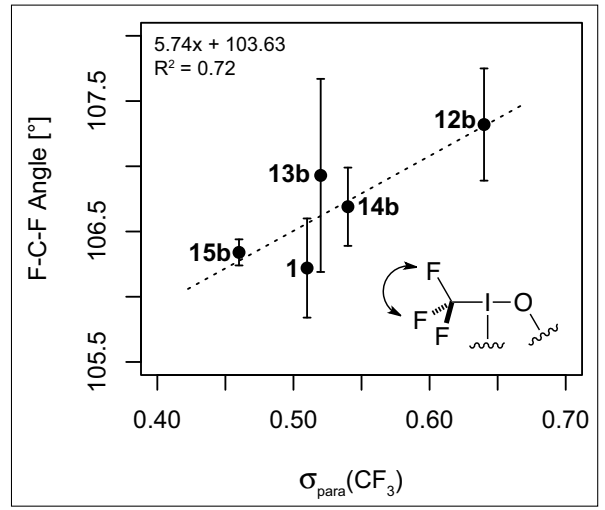

Fig. 4. Correlation of average F-C-F angles and $\sigma_{\text {para }}\left(\mathrm{CF}_{3}\right)$ corroborating increased $\mathrm{p}$-character in the $\mathrm{I}-\mathrm{CF}_{3}$ bond with increasing $\sigma_{\text {para }}\left(\mathrm{CF}_{3}\right)$.

\subsection{Reactivity of Type I Reagents}

In order to determine the reactivity of the reagents, they were subjected to a model reaction. ${ }^{[21,26]}$ Therefore, mixtures containing the substrate para-toluenesulfonic acid monohydrate $(0.1 \mathrm{M})$ and the appropriate reagent $\mathbf{1}, \mathbf{1 2 b}-\mathbf{1 5 b}(0.1 \mathrm{M})$ were monitored overnight in a mixture of $\mathrm{CDCl}_{3}: t \mathrm{BuOH} 5: 1$ at $298 \mathrm{~K}$ by ${ }^{19} \mathrm{~F}$ NMR spectroscopy. Thus, the concentrations of the individual species could be calculated at any given time based on the ${ }^{19} \mathrm{~F}$ integrals relative to an internal standard, $\alpha, \alpha, \alpha$ trifluorotoluene. Thereof, initial rates $\mathrm{v}_{0}$ were derived representing the solution phase reactivity of compounds $\mathbf{1}, \mathbf{1 2 b}-$ 15b. These rate data $\left(\mathrm{v}_{0}, \mathrm{k}_{\mathrm{rel}}\right)$ and the corresponding $\sigma_{\text {para }}(\mathrm{X})$ values derived before are summarized in Table 3.

Graphic Hammett-type analysis of $\ln \left(\mathrm{k}_{\mathrm{rel}}\right) \sim \sigma_{\text {para }}(\mathrm{X})$ is suggestive of linear dependencies for a reduced data set encom- passing reagents $\mathbf{1}, \mathbf{1 2 b}, \mathbf{1 3 b}$ and $\mathbf{1 5 b}$ (Fig. 5). Next, building on these relationships, predicted relative rates for compound 14b of 0.97 and 0.62 were obtained when using $\sigma_{\text {para }}(\mathrm{Cl})=0.27$ and $\sigma_{\text {para }}\left(\mathrm{CF}_{3}\right)=0.54$, respectively and consequently, the reagent was identified as an outlier. However, considering the structures of the reagents investigated, one notices the double-benzylic nature of the alcohol ligand in 14b in striking contrast to the alkyl based ligands in $\mathbf{1}$, 12b, 13b and 15b. This may lead to distorted $\sigma_{\text {para }}(\mathrm{X})$ values through additional packing effects, therefore hinting at the inherent weakness of a solid state structure/solution phase reactivity correlation. On the other hand, although compound $\mathbf{1 5 b}$ features a markedly different scaffold, its reactivity is well represented by the $\sigma_{\text {para }}(\mathrm{X})$ values further underlining the flexibility of the approach.

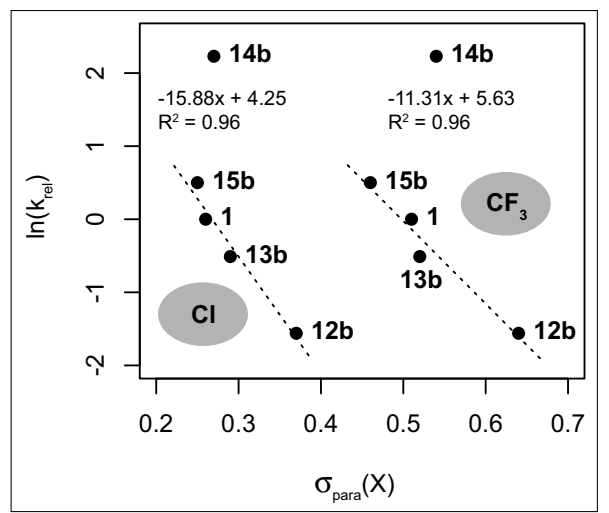

Fig. 5. Solution phase reactivities of reagents $1,12 b, 13 b$, and $15 b$ correlate with solid state structure derived $\sigma_{\text {para }}(X)$ values.

In keeping with the fact that a higher $\sigma(\mathrm{X})$ value implies a shorter $\mathrm{I}-\mathrm{X}$ bond, a shorter I-X bond relates to decreased solution phase reactivity, hence contrasting an earlier examination of the data. ${ }^{[21]}$ Indeed, the result that a longer $\mathrm{I}-\mathrm{CF}_{3}$ bond corresponds to higher reactivity is chemically more intuitive, since within the same motif $\mathrm{I}-\mathrm{CF}_{3}$ in analogous compounds a longer bond corresponds to a weaker bond.
In conclusion, analysis of the crystal structures of compounds $\mathbf{6}, \mathbf{1 2 a}-\mathbf{1 5 a}$ and 1, 12b-15b highlighted subtle electronic changes in the $\mathrm{I}-\mathrm{X}$ motif resulting from backbone modifications. Furthermore, these changes could be related to initial rates $\mathrm{v}_{0}$ and implied that the increased reactivity observed in the model reaction was resulting from weaker $\mathrm{I}-\mathrm{CF}_{3}$ bonds.

\subsection{Structure of Type II Reagents}

To this date, only two type II reagents have been reported in literature, 2 and 1-trifluoromethyl-5-nitro- $3 \mathrm{H}-1 \lambda^{3}, 2-$ benziodaoxol-3-one (16), ,27] a derivative featuring a nitrated aromatic core (Fig. 6). $\mathrm{X}$-Ray crystallography furnished $\mathrm{I}-\mathrm{CF}_{3}$ bond lengths of 2.219(4) $\AA$ and 2.200(6) $\AA^{3}$ for 2 and 16, respectively, and accompanying I-O lengths of 2.283(2) $\AA$ and 2.306(4) $\AA$. Most striking in contrast to type I reagents is the inversed bond length order I- $\mathrm{CF}_{3}<\mathrm{I}-\mathrm{O}$ leading to negative $\Delta_{\text {I-Х/I-O }}$ values of $-0.064 \AA$ (2) and $-0.106 \AA$ (16). Manifestation of the slightly lower transinfluence of the type II versus type I scaffold is found in the series $\mathrm{I}-\mathrm{CF}_{3}$ (type II) $<\mathrm{I}-\mathrm{CF}_{3}$ (type I). ${ }^{[22]}$ Likewise, this ordering denotes a further increase in p-character in the $\mathrm{I}-\mathrm{CF}_{3}$ bonding pattern corroborated by solid state structure derived F-C-F angles of $107.4 \pm 1.3^{\circ}(\mathbf{2})$ and $107.8 \pm 0.1^{\circ}(\mathbf{1 6})$.

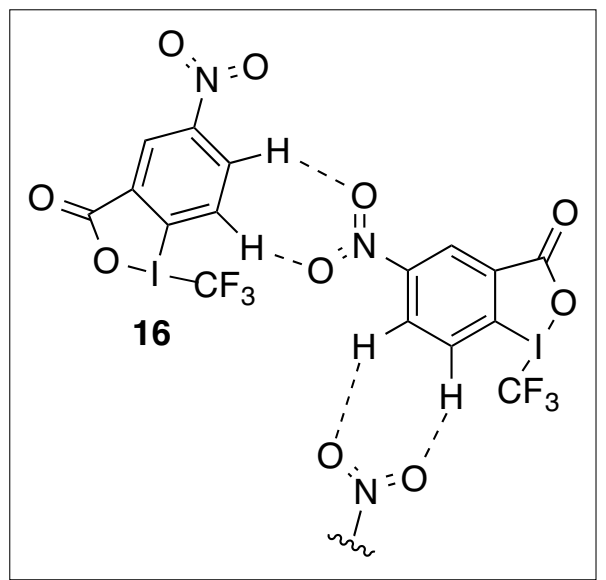

Fig. 6. Compound $\mathbf{1 6}$ forming hydrogen bond networks in the solid state.

The introduction of the $\mathrm{NO}_{2}$ functionality into the scaffold also led to hydrogen bond stabilized crystal packing, thereby significantly reducing the solubility of the reagent. Intermolecular $\mathrm{NO}_{2}-\mathrm{HC}_{\mathrm{Ar}}$ contacts of $2.41 \AA$ and $2.92 \AA$ were calculated. These additional stabilizing forces were also considered to be the reason for the higher thermal stability of derivative 16 when compared to 2 . Whereas for 2 a decomposition energy of $138 \mathrm{~kJ} / \mathrm{mol}$ and a maximal heat flow of $3.7 \mathrm{~kW} / \mathrm{mol}$ were reported based on differential scanning calorimetry measurements, 16 only exhibited values of $99 \mathrm{~kJ} / \mathrm{mol}$ and $2.2 \mathrm{~kW} / \mathrm{mol}$.

${ }^{\text {aRelative rate }} \mathrm{k}_{\mathrm{rel}}=\mathrm{v}_{0}(\mathrm{x}) / \mathrm{v}_{0}(\mathbf{1})$. 
Therefore, in accordance with these data and with the type I reactivity paradigm, 16 was initially deemed less reactive than 2 .

\subsection{Reactivity of Type II Reagents}

As reagent $\mathbf{1 6}$ is insoluble in the solvent combination $t \mathrm{BuOH}: \mathrm{CDCl}_{3}$ employed in type I reactivity studies, kinetic measurements were conducted in $\mathrm{MeCN}-\mathrm{d}^{3}{ }^{3}{ }^{[27]} \mathrm{To}$ this end, mixtures of para-toluenesulfonic acid monohydrate $(6 \mathrm{mM})$ and the appropriate reagent $(6 \mathrm{mM})$ were monitored at $298 \mathrm{~K}$ over the course of 12 minutes by ${ }^{19} \mathrm{~F}$ NMR spectroscopy. However, under these reaction conditions more than one product formed, such that only the decays of the reagents could be compared. For every compound six kinetic traces were recorded, necessitated by measurement uncertainties stemming from significant line-broadening upon addition of $p \mathrm{TsOH}$ to $\mathbf{2}$ and the generally low signal-to-noise ratio resulting from the low adopted concentrations. The experimental data obtained were either fitted with a linear (2) or an exponential rate law (16), both allowing for derivations of first order rate constants (Fig. 7).

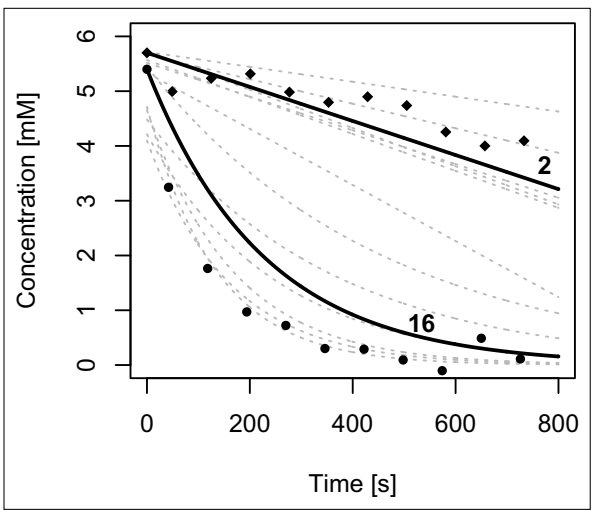

Fig. 7. Average decays of $\mathbf{2}$ and $\mathbf{1 6}$ (solid lines) in acidic media. Two experimental data series (diamond/circle) as well as all linear and exponential data fits (grey lines) are presented.

For reagent 2 a value of $\mathrm{k}_{2}=(5.46 \pm 2.23)$ $\times 10^{-4} \mathrm{~s}^{-1}$ was calculated and for $16 \mathrm{k}$ $=(4.43 \pm 2.15) \times 10^{-3} \mathrm{~s}^{-1}$ was obtained. Therefore, with a relative rate $\mathrm{k}_{16} / \mathrm{k}_{2}=8.1$ compound 16 was judged less stable under acidic conditions, contrary to initial expectations based on solid state structure derived arguments. However, due to the low solubility of $\mathbf{1 6}$ its applications are severely limited and the proof whether this increased lability also translates into increased reactivity is currently missing.

\section{Activation of Reagents}

Since the quest for more reactive type I/II reagents is time consuming and has not furnished greatly superior structures (yet), different strategies towards activation of $\mathbf{1}$ and $\mathbf{2}$ have been studied and exploited. An excellent example of how the reactivity of reagent 2 can be drastically increased is the $\mathrm{Zn}\left(\mathrm{NTf}_{2}\right)_{2}$-catalyzed electrophilic trifluoromethylation of primary and secondary alcohols. ${ }^{[28]} \mathrm{X}$-Ray crystallography indicated the formation of a complex accommodating two equivalents of reagent $\mathbf{2}$ and of the substrate in the coordination sphere of the $\mathrm{Zn}^{2+}$ ion, $\left[\mathrm{Zn}(\mathbf{2})_{2}(\mathrm{HOR})_{2}\left(\mathrm{H}_{2} \mathrm{O}\right)_{2}\right]^{2+}$, supporting the formation of a carboxylate complex (17) with increased iodonium character in solution. Indeed, when coordinated to the $\mathrm{Zn}^{2+}$ cation, the $\mathrm{I}-\mathrm{O}$ bond in 2 is elongated to 2.403(12) $\AA(+0.12 \AA)$ with a less pronounced diminution in I$\mathrm{CF}_{3}$ (2.195(16) $\AA,-0.024 \AA$ ). In addition, the F-C-F angle increased to $108.6 \pm 0.4^{\circ}$. The same fragment $\left[\mathrm{Zn}(2)_{2}\left(\mathrm{NTf}_{2}\right)\right]^{+}$was also identified by electron-spray ionization mass spectrometry (ESI-MS). Accordingly, product formation would result from coordination to the iodine core followed by reductive elimination or from a direct $\mathrm{S}_{\mathrm{N}} 2$ type displacement (Scheme 3). The potency of $\mathrm{M}\left(\mathrm{NTf}_{2}\right)_{\mathrm{n}}$-based activation of reagent 2 was further demonstrated in the oligomerization of THF.[29]

Later, extending on this $\mathrm{Zn}(\mathrm{II})$-based activation of 2 the carbon-functionalization of pyrrole and indole derivatives with reagent 1 was studied. ${ }^{[30]}$ Generally, this led to superior results, although $0.5-1$ equivalents of the promoter had to be employed. Consequently, to gain further insights into the mechanism of activation of reagent 1 preliminary solution phase studies on the putative $[\mathrm{Zn}(\mathbf{1})]^{2+}$ complex were carried out. ${ }^{[31]}$ The method of continuous variation (Job plot) pointed towards the formation of a $1: 1$ complex (i.e. $\mathrm{n}=1$ ) in $t \mathrm{BuOH}: \mathrm{CDCl}_{3}$ when $\mathrm{ZnBr}_{2}$ was employed (Fig. 8), con- trasting the 1:2 ratio found for 2 (vide supra). Furthermore, ${ }^{19} \mathrm{~F}$ NMR-based titrations furnished a binding constant $\mathrm{K}_{\mathrm{a}}$ $=234 \pm 25 \mathrm{M}^{-1}\left(\Delta \mathrm{G}^{\circ}=-13.5 \pm 0.3 \mathrm{~kJ} / \mathrm{mol}\right)$. In line with the findings delineated above, this is suggestive of an increased iodonium character facilitating the heteroaromatic functionalization.

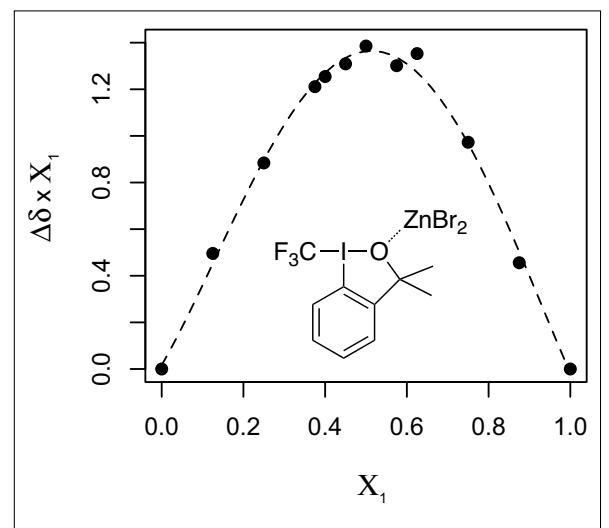

Fig. 8. ${ }^{19} \mathrm{~F}$ NMR-based Job plot indicating a 1:1 complexation of 1 with $\mathrm{ZnBr}_{2}$.

To date, the most widely applied and successful protocols using $\mathbf{1}$ or $\mathbf{2}$ involve copper-based catalyst systems. This strategy was pioneered when the electrophilic trifluoromethylation of $\alpha$-nitroesters with 1 was studied. ${ }^{[20,32]}$ In presence of $\mathrm{CuCl}(20$ mol\%) these reactions proceeded smoothly in DCM at room temperature, thereby providing access to interesting amino acid precursors in up to $99 \%$ yield based on ${ }^{19} \mathrm{~F}$ NMR spectroscopy (Scheme 4).

In several reactions, protonation of structures 1 and 2 to afford $[1 \mathrm{H}]^{+}$and $[2 \mathrm{H}]^{+}$, respectively, was indicated as the key step prior to heteroatom modification. ${ }^{[26,29,33]}$

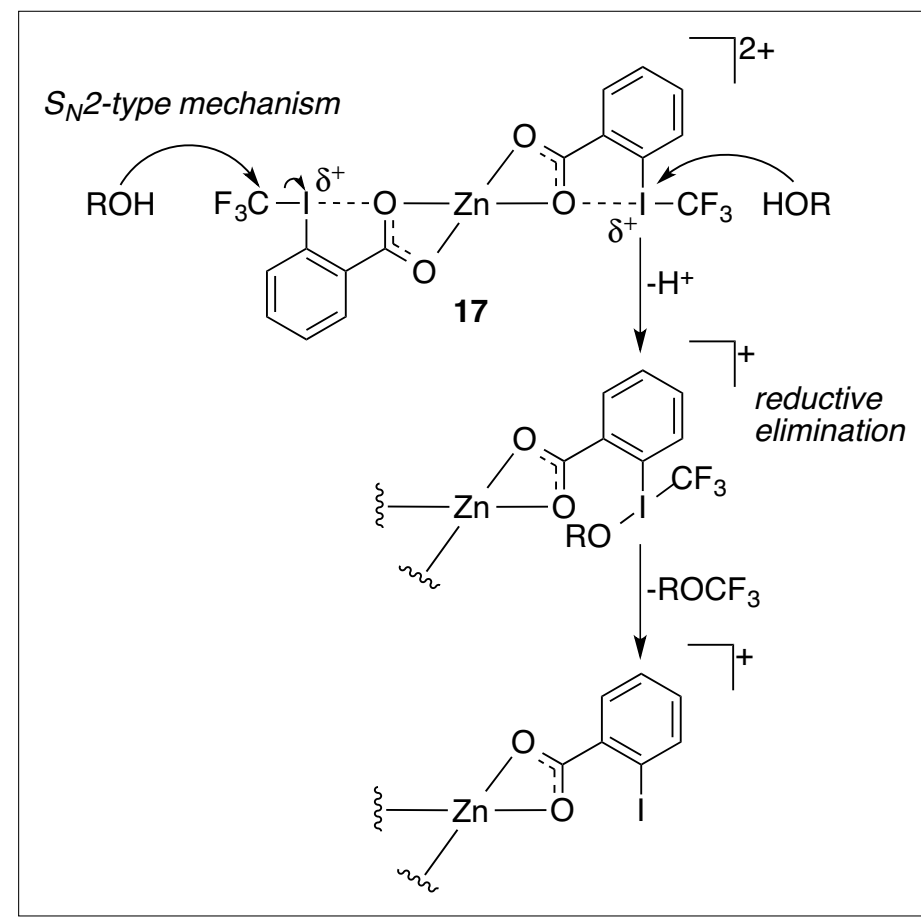

Scheme 3.

Mechanistic hypotheses for the $\mathrm{Zn}\left(\mathrm{NTf}_{2}\right)_{2}$ catalyzed trifluoromethylation of alcohols. 


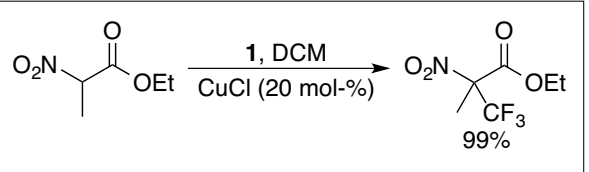

Scheme 4. CuCl-catalyzed trifluoromethylation with 1.

For example, the direct derivatization of $p \mathrm{TsOH}$ to $p \mathrm{TsOCF}_{3}$ proceeded in up to $90 \%$ yield. However, when the corresponding sodium salt ( $p \mathrm{TsONa})$ was employed, the desired ester was not formed. Subsequent addition of $\mathrm{HBF}_{4} \cdot \mathrm{OEt}_{2}$ restored the original reactivity, albeit with slightly diminished yields. ${ }^{[26]}$ Whilst studying the $\mathrm{HNTf}_{2}$-catalyzed functionalization of benzotriazole in $\mathrm{MeCN}$, the expected carbon-modified product could not be isolated. Rather, the trifluoromethyl moiety was transferred to the solvent, ostensibly forming the nitrilium species 18 which was subsequently intercepted by the nucleophile (Scheme 5).[33c] Thus, $N$-(trifluoromethyl)imine 19 was obtained in up to $70 \%$ isolated yield under optimized conditions. In addition, this protocol could be applied to indazole and a selection of pyrazole derivatives furnishing 37-53\% of the corresponding $N$-substituted products.

Lastly, dual activation of the substrate

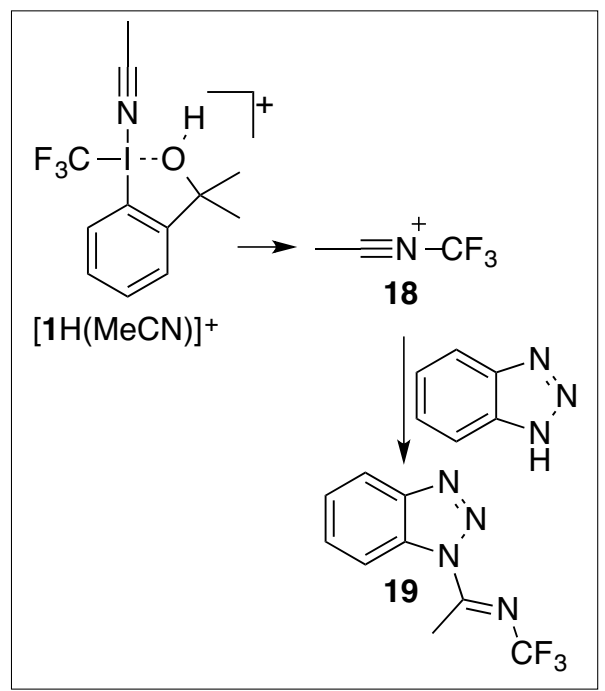

Scheme 5. Proposed reductive elimination from $[\mathbf{1 H}(\mathrm{MeCN})]^{+}$affording nitrilium ion 18 is followed by substrate trapping to produce 19. and the reagent was also found practical. This strategy was exploited in the direct $N$-trifluoromethylation of pyrazoles, triazoles and tetrazoles. ${ }^{[33 \mathrm{~d}]}$ Although benzotriazole could also be trifluoromethylated directly with 1, prior silylation with silica sulfuric acid (SSA) in 1,1,1,3,3,3-hexamethyldisilazane (HMDS) was found advantageous. This allowed for a reduction in the reaction temperature from $60{ }^{\circ} \mathrm{C}$ to $35^{\circ} \mathrm{C}$ whilst maintaining a $40 \%$ yield of $\mathbf{2 0}$ (Scheme 6). Further modifications to the protocol included an increase in concentration and addition of a fluoride scavenger, namely LiNTf. Finally, product 20 was formed in up to $87 \%$ yield. Moreover, the mode of activation of $\mathbf{1}$ was demonstrated to dictate selectivity. Whereas the HNTf (12 mol\%)/LiNTf $(2 \mathrm{~mol} \%)$ system afforded a ratio 20:21 of 84:2, relying on $\mathrm{BF}_{3} \cdot \mathrm{OEt}_{2}(5 \mathrm{~mol} \%)$ as catalyst and scavenger eroded this ratio to $48: 46$.

\section{Outlook}

While the concept of the electrophilic trifluoromethylation is old, the convenient syntheses of the stable, hypervalent iodinebased structures $\mathbf{1}$ and $\mathbf{2}$ has invigorated the field and led to a surge in reported applications. Conceivably, a detailed understanding of how molecular geometry influences the solution phase behavior of these intriguing structures will help guiding future endeavors towards the synthesis of tailored reagents. For example, compounds able to induce stereoinformation remained elusive so far. Therefore, future work will most certainly extend on mechanistic studies and also encompass functionalization of novel nucleophiles.

Received: March 31, 2014

[1] The Hansch-Fujita constant is defined as $\pi=\log$ $P_{\mathrm{X}}-\log P_{H}$ where $P_{\mathrm{H}}$ is the partition coefficient of benzene between 1-octanol and water and $P_{\mathrm{X}}$ the partition coefficient of a derivative.

[2] C. Hansch, A. Leo, D. Hoekman, 'Exploring QSAR: Volume 2: Hydrophobic, Electronic, and Steric Constants', American Chemical Society, Washington, DC, 1995.

[3] S. J. Blanksby, G. B. Ellison, Acc. Chem. Res. 2003, 36, 255.

[4] H. L. Yale, J. Med. Pharmaceut. Chem. 1959, 1, 121.

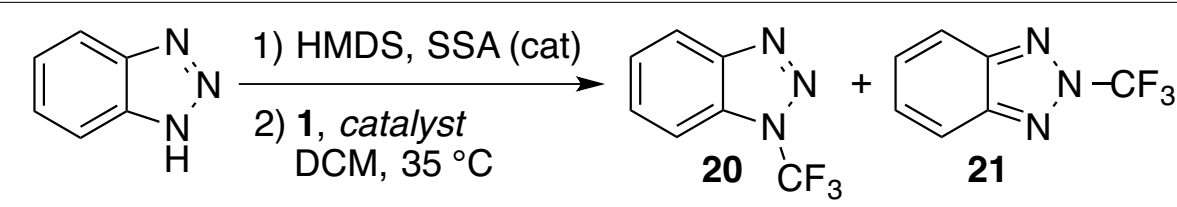

catalyst: $\mathrm{HNTf}_{2}(12 \mathrm{~mol}-\%), \mathrm{LiNTf}_{2}(2 \mathrm{~mol}-\%) \quad$ 20:21 = 84:2 $\mathrm{BF}_{3} \cdot \mathrm{OEt}_{2}(5 \mathrm{~mol}-\%) \quad \mathbf{2 0 : 2 1}=48: 46$
[5] M.A. McClinton, D. A. McClinton, Tetrahedron 1992, 48, 6555 .

[6] a) W. C. Smith, C. W. Tullock, E. L. Muetterties, W. R. Hasek, F. S. Fawcett, V. A. Engelhardt, D. D. Coffman, J. Am. Chem. Soc. 1959, 81, 3165; b) G. S. Lal, E. Lobach, A. Evans, J. Org. Chem. 2000, 65, 4830 .

[7] a) G. K. S. Prakash, R. Krishnamurti, G. A. Olah, J. Am. Chem. Soc. 1989, 111, 393; b) R. Krishnamurti, D. R. Bellew, G. K. S. Prakash, J. Org. Chem. 1991, 56, 984.

[8] S. Aït-Mohand, N. Takechi, M. Médebielle, W. R. Dolbier, Org. Lett. 2001, 3, 4271.

[9] J. Russell, N. Roques, Tetrahedron 1998, 54, 13771.

[10] Y. Takeyama, Y. Ichinose, K. Oshima, K. Utimoto, Tetrahedron Lett. 1989, 30, 3159.

[11] D. A. Nagib, M. E. Scott, D. W. C. MacMillan, J. Am. Chem. Soc. 2009, 131, 10875.

[12] a) D. A. Nagib, D. W. C. MacMillan, Nature 2011, 480, 224; b) Y. Yasu, T. Koike, M. Akita, Angew. Chem. Int. Ed. 2012, 51,9567; c) Y. Yasu, T. Koike, M. Akita, Chem. Commun. 2013, 49, 2037; d) S. Mizuta, K. M. Engle, S. Verhoog, O. Galicia-López, M. O’Duill, M. Médebielle, K. Wheelhouse, G. Rassias, A. L. Thompson, V. Gouverneur, Org. Lett. 2013, 15, 1250.

[13] L. M. Yagupol'skii, N. V. Kondratenko, G. N. Timofeeva, Russ. J. Org. Chem. 1984, 20, 103.

[14] a) U. Teruo, I. Sumi, Tetrahedron Lett. 1990, 31, 3579; b) T. Umemoto, S. Ishihara, J. Am. Chem. Soc. 1993, 115, 2156

[15] T. Umemoto, K. Adachi, S. Ishihara, J. Org. Chem. 2007, 72, 6905.

[16] P. Eisenberger, S. Gischig, A. Togni, Chem. Eur. J. 2006, 12, 2579.

[17] R. L. Amey, J. C. Martin, J. Org. Chem. 1979, 44, 1779.

[18] P. Eisenberger, I. Kieltsch, R. Koller, K. Stanek, A. Togni, Org. Synth. 2011, 88, 168

[19] V. Matoušek, E. Pietrasiak, R. Schwenk, A. Togni, J. Org. Chem. 2013, 78, 6763.

[20] I. Kieltsch, P. Eisenberger, A. Togni, Angew. Chem. Int. Ed. 2007, 46, 754.

[21] K. Niedermann, J. M. Welch, R. Koller, J. Cvengroš, N. Santschi, P. Battaglia, A. Togni, Tetrahedron 2010, 66, 5753.

[22] M. Ochiai, T. Sueda, K. Miyamoto, P. Kiprof, V. V. Zhdankin, Angew. Chem. 2006, 118, 8383.

[23] These calculations are only of approximative character as features of the 3,3-dimethyl$1 \lambda^{3}, 2$-benziodaoxole scaffold are transferred to modified structures whilst keeping the key moiety $\mathrm{X}=\mathrm{CF}_{3}$ constant.

[24] I. Fleming, 'Molecular Orbitals and Organic Chemical Reactions', John Wiley \& Sons Ltd, Chichester, 2009.

[25] a) A. D. Walsh, Faraday Discuss. 1947, 2, 18; b) H. A. Bent, Chem. Rev. 1961, 61, 275.

[26] R. Koller, Q. Huchet, P. Battaglia, J. M. Welch, A. Togni, Chem. Commun. 2009, 5993.

[27] N. Santschi, R. C. Sarott, E. Otth, R. Kissner, A. Togni, Beilstein J. Org. Chem. 2014, 10, 1.

[28] R. Koller, K. Stanek, D. Stolz, R. Aardoom, K. Niedermann, A. Togni, Angew. Chem. Int. Ed. 2009, 48, 4332.

[29] S. Fantasia, J. M. Welch, A. Togni, J. Org. Chem. 2010, 75, 1779.

[30] M. S. Wiehn, E. V. Vinogradova, A. Togni, J. Fluorine Chem. 2010, 131, 951.

[31] N. Santschi, Ph.D. Thesis ETH Zürich No. 21317, 2013.

[32] I. Kieltsch, P. Eisenberger, K. Stanek, A. Togni, Chimia 2008, 62, 260.

[33] a) N. Santschi, A. Togni, J. Org. Chem. 2011, 76, 4189; b) N. Santschi, P. Geissbühler, A. Togni, J. Fluorine Chem. 2012, 135, 83; c) K. Niedermann, N. Früh, E. Vinogradova, M. S. Wiehn, A. Moreno, A. Togni, Angew. Chem. Int. Ed. 2011, 50, 1059; d) K. Niedermann, N. Früh, R. Senn, B. Czarniecki, R. Verel, A. Togni, Angew. Chem. Int. Ed. 2012, 51, 6511. 